\title{
Modeling the Impact of Climate and Fertilizer on Barley Production
}

\author{
Birhan Ambachew Taye, Fasiledes Fetene Asfaw, Bantie Getnet Yirsaw, Alemayehu Amsalu Alen \\ Department of Statistics, Woldia University, Woldia, Ethiopia \\ Email address: \\ workneshambachew@gmail.com (B. A. Taye), fasiledesfetene4@gmail.com (F. F. Asfaw), bantiegetnet@gmail.com (B. G. Yirsaw), \\ alexso21a@gmail.com (A. A. Alen)
}

\section{To cite this article:}

Birhan Ambachew Taye, Fasiledes Fetene Asfaw, Bantie Getnet Yirsaw, Alemayehu Amsalu Alen. Modeling the Impact of Climate and Fertilizer on Barley Production. American Journal of Biological and Environmental Statistics. Vol. 7, No. 2, 2021, pp. 44-51. doi: $10.11648 /$ j.ajbes.20210702.12

Received: March 19, 2021; Accepted: May 21, 2021; Published: May 31, 2021

\begin{abstract}
Agriculture is a confirmed path to success. No region of the world has developed a diverse, modern economy without first establishing a successful foundation in agriculture. Food security is an enduring critical challenge in Ethiopia. The 2015 El Niño drought is one of the strongest droughts that have been recorded in Ethiopian antiquity. The study aims to evaluate the impacts of climate change and fertilizers applied on barley yield per hectare from 1987 to 2017 using an autoregressive distributed lag to cointegration approach. The mean barley yield was 11.47 quintal per hectare. The Long run bounded test for cointegration among the variables show signal of a long-run relationship with a short run among climate change, fertilizers applied and barley yield per hectare. Based on the value of adjusted $\mathrm{R}^{2}$, the explanatory variables explained almost $76 \%$ of the variation in the yield of barley. In the long run estimates every $1 \%$ rise in current average dap decrease the yield per hectare of barley by $28.76 \%$ at citrus paribus and a $1 \%$ rise in current precipitation and rainfall increase the yield of barley by $2.768 \%$ and $0.41 \%$ respectively keeping the effect of one variable to the other constant. The speed of adjustment is 0.381557 which is highly significant indicating the speed of the adjustment back to the long run equilibrium after a short run shock.
\end{abstract}

Keywords: Agriculture, Autoregressive Distributed Lag, Cointegration

\section{Introduction}

Agriculture is a proven track to wealth. No region of the world has developed a diverse, modern economy without first establishing a successful foundation in agriculture. This is going to be critically true for Africa where, today, close to $70 \%$ of the population are involved in agriculture. Crop yield per area (amount of crop harvested per amount of land cultivated) is the most frequently used impact indicator for agricultural productivity activities. Crop yields are inevitably affected by many factors, these are weather, input price, changes in farming practices, amounts of fertilizer used, quality of seed varieties, and use of irrigation [1].

Ethiopia enjoyed remarkable growth in agricultural production and overall real incomes (GDP/capita) from $2004 / 05$ to $2008 / 09$, due to a combination of factors, including good weather, increased efforts in agricultural extension, increased usage of fertilizer. The reality of
Ethiopia's agriculture and food security situation is complex because of variations across space within Ethiopia as well as variations over time due to changes in policies, weather shocks, and other factors [2].

There has been no much research on impact of fertilizers on crop with respect to the Amhara region of Ethiopia. For example, [3] found that the fertilizers credit access had a significant impact on teff but not on maize and wheat. The researcher used total amount of fertilizer, as a limitation this doesn't show which fertilizer is more effective on the yield of crops.

There have been limited scientific evidences on impacts of climate change on wheat and barley production in Ethiopia. For instance different scholars addressed the economic impacts of climate change in Ethiopia were based on aggregate agricultural crops produced $[4,5]$. But in reality; climate change affects different crops differently. Therefore the objective of the study was assessing the impact of climate 
variables and type of fertilizers on crop production in Amhara region using time series models.

\section{Data and Methodology}

The data for the research were secondary data from the year 1987-2017 G. C. Climate variables were taken from national metrological agency and NASA climate data center. Selected cereal yields and amount of fertilizers applied were taken from yearly mehere season of private peasant agriculture and production report from Central statistical agency (CSA) of Ethiopia.

The variables in the study were barley production in quintal/hectare collected from CSA annual report of Ethiopia, selected indicator of climatic variables was average temperature in degree Celsius and precipitation in $\mathrm{mm} / \mathrm{d}$ collected from the NASA satellite for world climate and rainfall in $\mathrm{mm}$ from national meteorology of Ethiopia. Type and amount of fertilizers used (average urea and average dap) in quintal/hectare from CSA annual report.

\subsection{Time Series Analysis}

A time series is a series or sequence of data points measured typically at successive times. These data points are commonly equally spaced in time. The first step in time series analysis is to check stationary process of the data. Stationary series has the property that the first and second moments are time invariant. In particular, the mean vector and covariance matrix of a weakly stationary series are constant over time [6]. For a stationary time series $y_{t}$, we define its mean vector and covariance matrix as:

$$
\begin{gathered}
E\left(y_{t}\right)=\mu, \\
\sigma_{h}=E\left(y_{t}-\mu\right)\left(y_{t-h}-\mu\right)=\sigma(-h) \text { where, } t, h=0,1,2 \ldots . .
\end{gathered}
$$

the expectation is taken element by element over the joint distribution of $y_{t}$. The mean $\mu$ is a m-dimensional vector consisting of the unconditional expectations of the components of $y_{t}$. The covariance matrix $\sigma_{h}$ is a $m \times m$ matrix. The diagonal element of $\sigma_{h}$ is the variance of $y_{i t}$, whereas the $(i, j)^{t h}$ element of $\sigma_{h}$ is the covariance between $y_{i t}$ and $y_{j t}$.

\subsection{Autoregressive Distributed Lag (ARDL) Model}

Since the data for this research is annual it is better to use ARDL rather than ARIMA and GARCH. As non-stationary variables change in time, so OLS estimates show high tvalues by mistake as they become inflated due to common time component. In econometric it is called spurious results where $\mathrm{R}^{2}$ value of the model becomes higher than the Durbin-Watson Statistic. To avoid a spurious regression ARDL model was introduced by Pesaran [7] in order to incorporate I (0) and I (1) variables in the same estimation. This model is an ordinary least square (OLS) based model which is applicable for both non-stationary time series as well as for times series with mixed order of integration.

General ARDL (p, q) model is given by

$$
y_{t}=\alpha_{0}+\alpha_{1} t+\sum_{i=1}^{p} \delta_{i} y_{t-i}+\sum_{j=1}^{k} \sum_{i=0}^{q} \beta_{j i} x_{j, t-i}+\varepsilon_{t}
$$

Where $y_{t}$ and $x_{t}$ are stationary variables. A critical element in the specification of ARDL models is the determination of the lag length of the model. Over fitting (selecting a higher order lag length than the true lag length) causes an increase in the mean-square forecast errors of the model and that under fitting the lag length often generates autocorrelated errors [6]. There is no hard-and-fast-rule on the choice of lag length. It is basically an empirical issue. As noted in Gujarati [8], there is no a prior guide as to what the maximum length of the lag should be.

The initial maximal lag in this research has been set equal to two, which is the maximal order recommended by Pesaran [9] for annual data. Also, from Wooldridge [10]: A Modern Approach with annual data, the number of lags is typically small, 1 or 2 lags in order not to lose degrees of freedom.

In order to empirically analyze the long-run relationships and short run dynamic interactions among the variables of interest (barley, average dap, average urea, precipitation, temperature and rainfall) we apply the (ARDL) Bound test technique. After checking and estimating the long run relationship of the variables, then estimate the appropriate short run parameters by using Error Correction model (ECM).

\subsection{Model Adequacy Checking}

The most useful and informative diagnostic checks deal with determining whether or not the assumptions underlying the innovation series are satisfied by the residuals of the calibrated ARDL model.

When fitting a model to time series variables the model should be stable and the estimated innovations or residuals are assumed to be independent, homoscedastic and normally distributed. The model diagnostics can be checked using stability test, specification test, residual autocorrelation test, heteroskedasticity test, and $\mathrm{ARCH}$ test.

\subsection{Cointegration and Error Correction Model (ECM)}

\subsubsection{Cointegration Test}

Cointegration often means that a linear combination of individually unit-root nonstationary time series becomes a stationary and invertible series. The linear combination $\phi$ vector is called a cointegrating vector. A process consisting of cointegrated variables is called a cointegrated process [11].

Cointegration is concerned with the analysis of long run relations between integrated variables and reparametrizing the relationship between the considered variables into an Error Correction Model. In this model the ARDL bound test is used.

For the purpose of this study Autoregressive Distributed Lag (ARDL) bound test approach developed by Pesaran, 
Shin and Smith (2001) was used. The general form of the model in the research was:

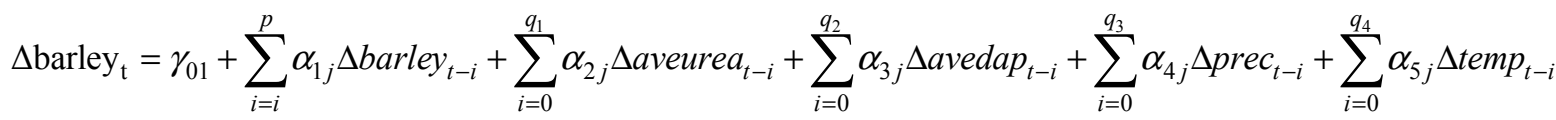

$$
\begin{aligned}
& +\sum_{i=0}^{q_{4}} \alpha_{6 j} \text { srain }_{t-i}+\delta_{1} \text { barley }_{t-i} \delta_{2} \text { aveurea }_{t-1}+\delta_{3} \text { avedap }_{t-1}+\delta_{4} \text { prec }_{t-1}+\delta_{5} \text { temp }_{t-1}+\delta_{6} \text { rain }_{t-1}
\end{aligned}
$$

Where $\delta^{s}$ and $\pi^{s}$ are long-run coefficients, $\Delta$ is first differences, $\alpha^{s}$ are short run coefficients, $t$ is time trend and $\varepsilon_{i}^{s} \sim\left(\mu, \sigma^{2} I\right)$.

The bound test approach for the long-run relationship between the variables of interest and the exogenous variables are based on the Wald test (F-statistic), by imposing restrictions on the long-run estimated coefficients of one period lagged level of the variables of interest and the exogenous variables to be equal to zero, that is,

$$
\begin{aligned}
& H_{0}: \delta_{1}=\delta_{2}=\delta_{3}=\delta_{4}=\delta_{5}=\delta_{6}=0 \\
& H_{1}: \delta_{1} \neq \delta_{2} \neq \delta_{3} \neq \delta_{4} \neq \delta_{5} \neq \delta_{6} \neq 0
\end{aligned}
$$

The calculated F-statistic is compared to the tabulated critical value in Pesaran, Shin and Smith (2001). The explanatory variables are assumed to be integrated of order zero, or $I(0)$ for values of the lower bound, while the upper bound values assumed they are integrated of order one, or $I(1)$. Therefore, the decision rule is that if computed Fstatistic falls below the lower bound value, $I(0)$, the null hypothesis (no cointegration) cannot be rejected. Contrarily, if the computed F-statistic exceeds the upper bound value, $I(1)$ then it can be concluded that variables of interest and the exogenous variables co-integrated [7].

\subsubsection{Error Correction (EC) of the ARDL Model}

The EC coefficient shows how fast variables restore to their equilibrium value. The $E C M_{t-1}$, which measures the adjustment to restore equilibrium in the dynamic model. If the ECM coefficient is significance ensuring the long run equilibrium can be attained [12]. ECM in the research was given by:

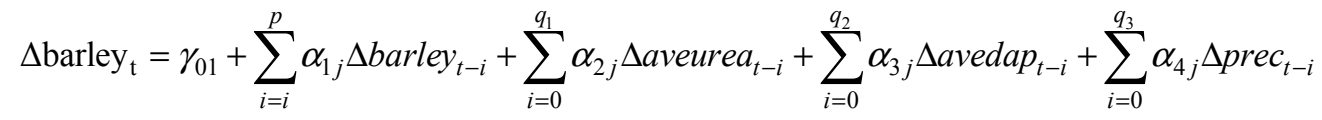

$$
\begin{aligned}
& +\sum_{i=0}^{q_{4}} \alpha_{5 j} \Delta t e m p_{t-i}+\sum_{i=0}^{q_{4}} \alpha_{6 j} \Delta \operatorname{rain}_{t-i}+\phi_{1} E C T_{t-1}+\varepsilon_{1 t}
\end{aligned}
$$

\section{Result and Discussion}

\subsection{Descriptive Analysis}

Table 1 shows descriptive statistic of annual barley production by private peasant, Fertilizers applied and climate variables from 1987 to 2017. The mean annual yield of barley was $11.47 \mathrm{q} / \mathrm{ha}$. The amount of urea and DAP fertilizers used for the two crops by averages were $0.65 \mathrm{q} / \mathrm{ha}$ and $0.81 \mathrm{q} /$ ha respectively. The mean annual values for the three selected climatic variables were $21.48^{\circ} \mathrm{c}, 111.69 \mathrm{~mm}$ and $3.51 \mathrm{~mm} / \mathrm{d}$ for temperature, rainfall and precipitation respectively.

Table 1. Descriptive Statistics.

\begin{tabular}{llllll}
\hline & BARLEY & TEMPS & RAIN & PREC & UREA \\
\hline Mean & 11.47129 & 21.47968 & 111.6944 & 3.507264 & 0.650538 \\
Median & 10.10000 & 21.40000 & 113.6822 & 3.640909 & 0.650000 \\
Maximum & 19.74000 & 25.14000 & 142.1351 & 4.851818 & 0.812043 \\
Minimum & 7.110000 & 18.57000 & 60.67500 & 1.963636 & 0.820000 \\
Std. Dev. & 3.666677 & 1.372529 & 16.81541 & 0.836613 & 0.303333 \\
Observations & 31 & 31 & 31 & 31 & 0.134651 \\
\hline
\end{tabular}

Average temperature shows an increasing trend from 1987 to 2017 ( $\mathrm{y}=0.0997 \mathrm{x}-177.43)$. By comparison, the total precipitation showed a slight downward trend $(y=-0.0188 \mathrm{x}+$ 41.053).

\subsection{Inferential Statistics}

\subsubsection{Unit Root Test}

First it is recommended to plot the series in order to look the pattern of the data weather to include the trend part or not. 
barley

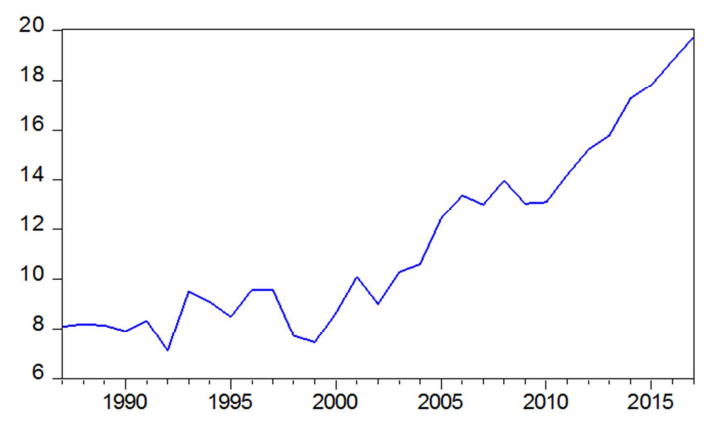

avedap

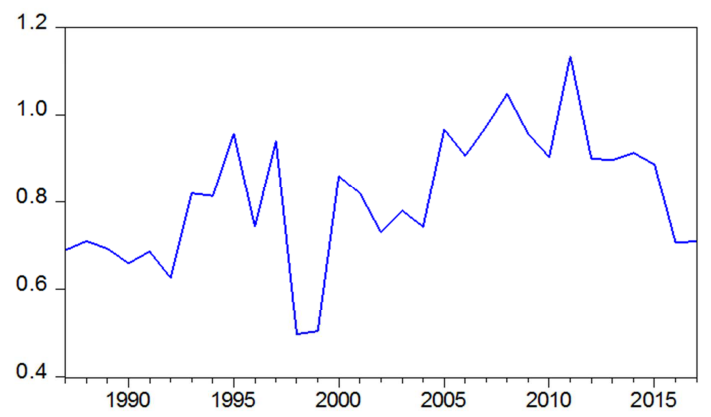

rain

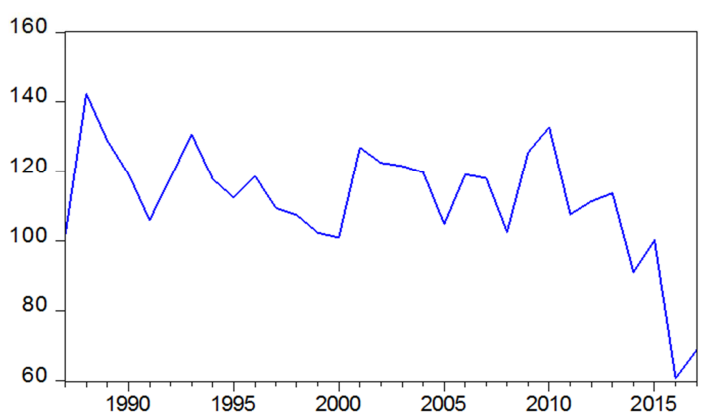

aveurea

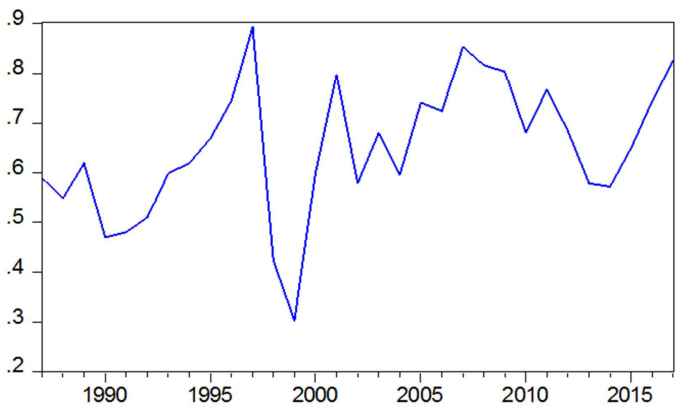

prec

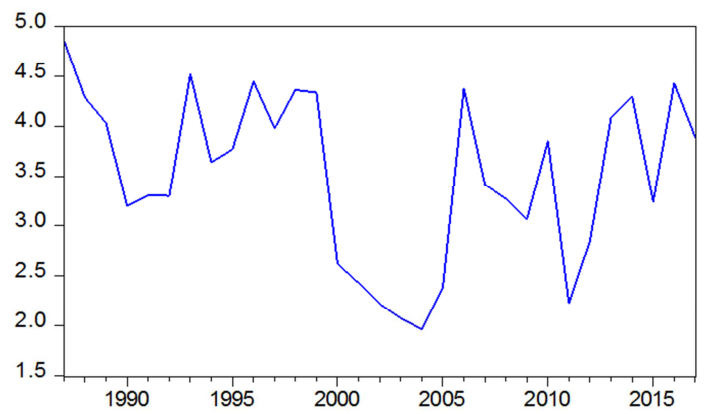

temps

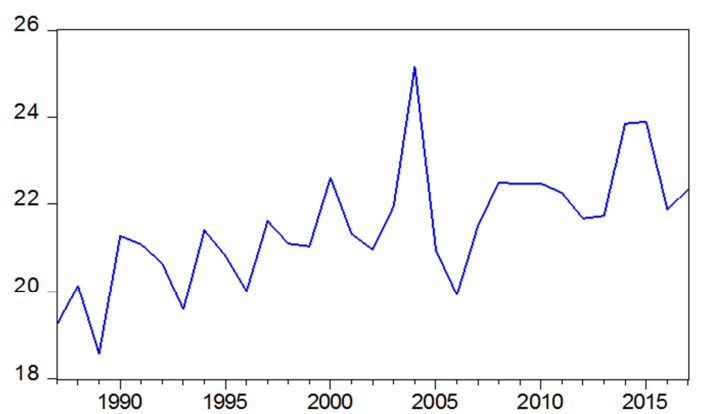

Figure 1. Time series plot of variables.

From above figure the mean and variances of some variables seems increase with time, implies the series are not stationary. Since the decision is subjective, we undertake a formal test for unit root test. In the presence of variables integrated of order two, we cannot interpret the values of F- statistics [7]. From the table below the variables are mixed order of integration and no variables are integrated of order two, implies ARDL model is appropriate. Temperature, Urea and DAP are stationary at level the rest are stationary after first difference.

Table 2. Stationarity test.

\begin{tabular}{|c|c|c|c|c|c|}
\hline \multirow{2}{*}{ Variables } & \multicolumn{2}{|c|}{ ADF at Level } & \multicolumn{2}{|c|}{ ADF at first difference } & \multirow{2}{*}{ Order } \\
\hline & Values & p-value & Values & P-values & \\
\hline Barley & -1.59 & 0.772 & -6.69 & 0.001 & I (1) \\
\hline Temperature & -6.06 & 0.001 & - & - & $\mathrm{I}(0)$ \\
\hline Rainfall & -3.41 & 0.07 & -8.13 & 0.001 & I (1) \\
\hline Precipitation & -3.21 & 0.102 & 6.82 & 0.001 & I (1) \\
\hline Urea & -4.07 & 0.017 & - & - & $\mathrm{I}(0)$ \\
\hline DAP & -3.57 & 0.049 & & & $\mathrm{I}(0)$ \\
\hline
\end{tabular}

Practical problem in the estimation of time series and econometrics models relates to the number of variables to be included in the model and the maximum lag length to be applied. Time series and econometrics analysis depends critically on the lag order selected. Different lag orders can significantly affect the substantive interpretation of the estimates when those differences were large enough [13]. The maximum lag order selected by minimum AIC is two. 


\subsubsection{ARDL Bound Test for Cointegration}

The computed F-statistic and critical value (at the 5\% significance level). We have evidence to reject the null hypothesis of no cointegration because 5.22 is higher than I (1) of PSS (2001) critical value at 5\% level of significance.

Table 3. ARDL bound test.

\begin{tabular}{lllll}
\hline F-bound test & barley & Sign. & I (0) & I (1) \\
\hline F-statistic & 5.22 & $10 \%$ & 3.087 & 4.277 \\
$\mathrm{k}=5$ & & $5 \%$ & 3.673 & 5.002 \\
& & $1 \%$ & 5.095 & 6.77 \\
\hline
\end{tabular}

\subsubsection{Short Run Parameter Estimation and Interpretation}

From the table below the short-run coefficients estimates show the dynamic adjustment of all variables. The short run coefficients for D (average urea), D (average urea (-1)), D (average dap), D (prec), D (rain (-1)), D (temperature) and D (temperature (-1)) are statistically significant at the 5\% level of significance. The magnitude of the adjusted $\left(\mathrm{R}^{2}\right)$ and the F-statistics show the model goodness of fit. Based on the value of adjusted $\mathrm{R}^{2}$, the explanatory variables explained almost $76 \%$ of the variation in the production of barley and the F-statistics shows the model is well fitted.

Table 4. Short run parameter estimation

\begin{tabular}{|c|c|c|c|c|}
\hline \multirow{2}{*}{ Regressor } & \multicolumn{2}{|c|}{ Error Correction Representation } & \multirow{2}{*}{ t-statistic } & \multirow{2}{*}{ Prob } \\
\hline & Coefficients & std. error & & \\
\hline $\mathrm{C}$ & -0.733735 & 0.221384 & -3.314312 & 0.0051 \\
\hline $\mathrm{T}$ & 0.443967 & 0.084822 & 5.234129 & 0.0001 \\
\hline D (AVEUREA) & 6.870459 & 1.121342 & 6.126997 & 0.0005 \\
\hline D (AVEUREA (-1)) & 6.568769 & 1.202268 & 5.463646 & 0.0005 \\
\hline D (AVEDAP) & -4.437762 & 1.279058 & -3.469553 & 0.0038 \\
\hline $\mathrm{D}(\mathrm{PREC})$ & 1.056267 & 0.257176 & 4.107170 & 0.0011 \\
\hline D (RAIN (-1)) & -0.084793 & 0.013954 & -6.076724 & 0.0005 \\
\hline D (TEMPS) & -0.389559 & 0.078432 & -4.966810 & 0.0002 \\
\hline D (TEMPS $(-1))$ & 0.350777 & 0.088972 & 3.942580 & 0.0015 \\
\hline CointEq $(-1)^{*}$ & -0.381557 & 0.058519 & -6.520171 & 0.0001 \\
\hline R-squared & 0.834689 & Mean dependent var & 0.398276 & \\
\hline Adjusted R-squared & 0.756384 & S. D. dependent var & 0.993342 & \\
\hline S. E. of regression & 0.490289 & AIC & 1.679155 & \\
\hline Log likelihood & -14.34775 & HQIC & 1.826817 & \\
\hline F-statistic & 10.65942 & Durbin-Watson stat & 2.765895 & \\
\hline Prob (F-statistic) & 0.000010 & & & \\
\hline
\end{tabular}

In the short run, the current year barley production is affected positively by current and previous year amount of urea used, previous year temperature, current year precipitation and current year rainfall and also affected negatively by previous year rainfall and current year temperature and DAP. The change of time itself affects the yield positively.

A $1 \%$ increase in current DAP make the yield of barley to decrease by $4.43 \%$ quintal per hectare. A $1 \%$ increment in current urea improved the yield of barley by $6.87 \%$ and when current temperature rises by $1 \%$ the yield to decrease by $0.39 \%$ in the short run. A $1 \%$ rise in current precipitation increase the yield by $1.05 \%$. If the current amount of rainfall rises by $1 \%$ the yield increase by $0.025 \%$.

The coefficient of the error correction term that captures the speed of adjustment towards the long run equilibrium is found with the correct sign and magnitude. Speed of adjustment is -0.381557 which is highly significant indicating the speed of the adjustment back to the long run equilibrium after a short run shock. The estimated value of the coefficient indicates that about $38.15 \%$ of deviations from the long run equilibrium is adjusted in the current year, in the next year another $38.15 \%$ will be adjusted and the rest $23.7 \%$ will be adjusted in the third year. This shows that once the disequilibrium happens it takes around two and half year to correct any deviation from the long run equilibrium.

\subsection{Long Run Parameter Estimates}

As a result of cointegration among variables is confirmed. So, the ARDL bound test for the short-run and long-run relationships between barley yield, climate variables and fertilizer used is estimated. The estimated coefficients in Table below shows, in the long run average DAP have high negative significant impact. Precipitation and rainfall have a positive significance impact but average urea and temperature have no significant impact on the amount of yield per hectare of barley at $5 \%$ level of significance. In the long run estimates every $1 \%$ decrease in current average dap increase the yield per hectare of barley by $28.76 \%$ at citrus paribus and a $1 \%$ rise in current precipitation and rainfall increase the yield of barley by $2.768 \%$ and $0.41 \%$ respectively keeping the effect of one variable to the other constant.

Table 5. Long run parameter estimation.

\begin{tabular}{lllll}
\hline \multirow{2}{*}{ Variables } & \multicolumn{2}{l}{ Long-run estimates } & \multirow{2}{*}{ t-statistic } & \multirow{2}{*}{ prob } \\
\cline { 2 - 5 } & coefficients & std. error & & \\
\hline Urea & -3.494692 & 5.029044 & -0.694902 & 0.4985 \\
Dap & -28.76323 & 11.31615 & -2.541787 & 0.0235 \\
Prec & 2.768306 & 0.865427 & 3.198774 & 0.0064 \\
Rain & 0.409652 & 0.149469 & 2.740723 & 0.0159 \\
Temp & -1.622681 & 0.837329 & -1.937926 & 0.0731 \\
\hline
\end{tabular}




\subsection{Model Diagnostic}

At this stage, an evaluation of the tentative model based on the estimated residual properties is to be performed.

\subsubsection{Stability Test}

The stability of the coefficients in the model are checked by CUSUM and CUSUMSQ test conducted based on the

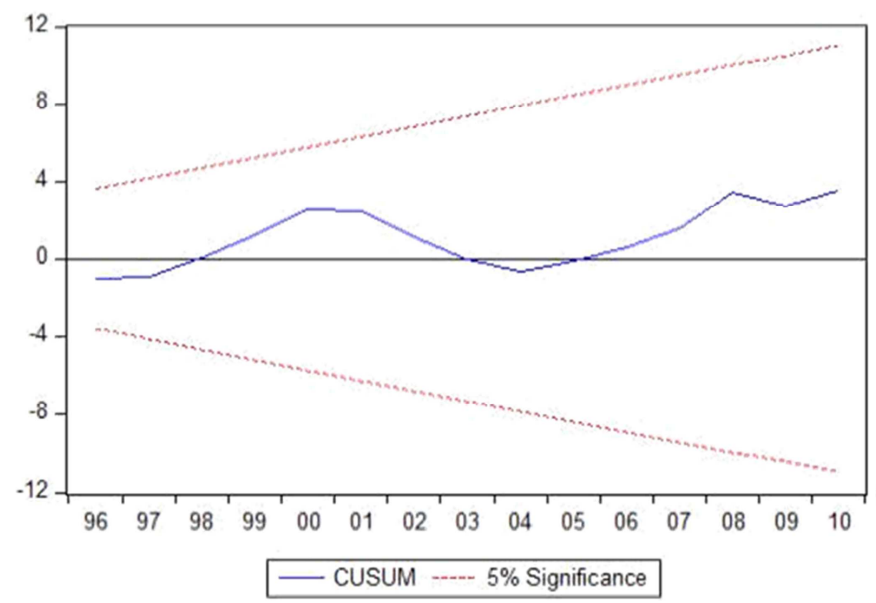

recursive regression residuals as suggested by Brown et al [14]. The stability of the long-run coefficients is tested by the short-run dynamics. Once the ECM model has been estimated, the cumulative sum of recursive residuals (CUSUM) and the CUSUM of square tests are applied to assess the parameter stability [15]. From the figure below we conclude parameters are stable.

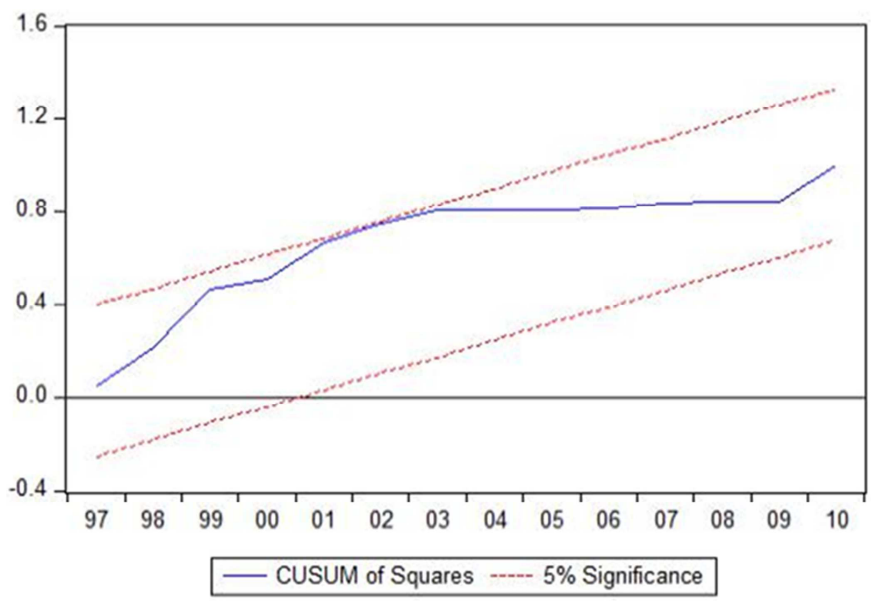

Figure 2. Stability test.

\subsubsection{Specification Test}

Another potential problem may be omitted variable bias where some temperature-related and fertilizers-related variables such as (disease or pests, NPK, NPS, natural fertilizers, sunshine, humidity etc) that affect cereal yield but have been left out of ARDL model. Ramsey (1969) regression specification error test (RESET) for omitted variables is used. The purpose of this test is to provide evidence concerning the existence or non-existence of structural breaks in the ARDL model for barley. the null and alternative hypothesis is given by:

$H_{0}$ : the model is specified correctly vs $H_{1}$ : the model is not correctly specified

Table 6. Ramsey RESET test.

\begin{tabular}{llll}
\hline & Value & Df & Probability \\
\hline t-statistic & 1.115958 & 16 & 0.2809 \\
F-statistic & 1.245362 & $(1,16)$ & 0.2809 \\
\hline
\end{tabular}

Therefore, Ramsey RESET test for functional form specification accepts the regression specification of the dynamic model. Furthermore, failing to reject the null in Ramsey reset test also further confirms that our model did not suffer from omitted variable bias [16].

\subsection{Autocorrelation and Homoscedasticity Test}

Autocorrelations of the residuals are tested by using the Breusch-Godfrey Serial Correlation LM Test and the homoscedasticity test are tested by Breusch-Pagan-Godfrey test.

From the table below we are in favor of not rejecting the null hypothesis of the residuals are serially uncorrelated because the p-values of the F-statistic is 0.9183 for the models, implying the residuals are serially uncorrelated

Table 7. Breusch-Godfrey test.

\begin{tabular}{ll}
\hline Statistic & Residual \\
\hline F-statistic & 0.085745 \\
p-value & 0.9183 \\
\hline
\end{tabular}

From table below there is no evidence to say the variance of the residuals are not constant since the p-value 0.8222 is greater than the $5 \%$ level of significance, implies the homoscedastic of residual assumption is satisfied.

Table 8. Breusch-Pagan-Godfrey test.

\begin{tabular}{ll}
\hline Statistic & Barley \\
\hline F-statistic & 0.4712 \\
p-value & 0.8222 \\
\hline
\end{tabular}

\subsection{Granger Causality}

Three types of Granger causalities were applied to find the causality: (1) Short-run causality the Wald test was applied for all the lag independent variables using the joint F test; (2) long-run causality investigated by verifying the coefficient of the error correction term (it should be between 0 and 1 with a negative sign), which implies convergence of the system back to the long-run equilibrium position, (3) joint (short-run and long-run) causality - the Wald test was applied to both the lagged independent variables and the error correction term using the joint $\mathrm{F}$ test [17]. From table below in the short run urea, DAP and precipitation Granger cause barley productivity. In the long run all variables Granger cause barley yield because the ECT is negative and also between 0 and 1 finally in the joint causational, all variables Granger 
cause barley yield.

Table 9. Granger Causality Test.

\begin{tabular}{llll}
\hline Variables & F-Statistics (Probability) & t-Statistics (Long-Run) & Joint (Short- and Long-Run) \\
\hline & (Short-Run) & & \\
\hline Urea & $11.49207(0.0044)$ & $4.393903(0.0006)$ & $11.31134(0.0012)$ \\
DAP & $6.240988(0.0256)$ & $"$ & $9.772751(0.0022)$ \\
Precipitation & $10.18507(0.0065)$ & $"$ & $9.745318(0.0022)$ \\
Rainfall & $0.993788(0.3357)$ & $"$ & $9.761519(0.0022)$ \\
Temperature & $0.009921(0.9221)$ & $"$ & \\
\hline
\end{tabular}

\section{Conclusion}

Increasing cereal crops production is one of the most important determinants of economic of one country. This study focused on determining empirically the impact of major factors on barley yield.

Based on the analytical results of this work, two issues can be resolved. One is whether the threat of climate change impacted the barley yield per hectare in Amhara region and the other is whether average quantity of fertilizer type used increased the barley yield per hectare. In this paper, we examined the relationships among barley yield per unit hectare with precipitation, temperature, rainfall; average urea and average DAP in Amhara region from 1987 to 2017 by using an Autoregressive Distributed Lag (ARDL) to cointegration model.

In the short run current amount of average urea, previous year of Average urea, precipitation, previous year temperature and current amount of rainfall have positive impacts on the barley yield per hectare but temperature, average DAP and previous year rainfall affects yield of barley negatively and also the time change have a positive impact. The coefficient of error correction term ecm (-1) which is highly significant indicating that there is a disequilibrium that can be adjusted in the long run. The estimated value of the coefficient indicates that disequilibrium in barley is offset by the short run adjustment in the same year.

In the long run precipitation and rain has a positive impact on the yield of barley but DAP have highly negative impact. Temperature and average urea have no impact in the long run.

\section{Recommendation}

Depending on the result of this research we have several policy implications that could ensure continuous increases in the barley yield per unit hectare and food security under climate change and fertilizers used in Amhara region. Average urea could be e ective measures but average DAP have high negative impact in the yield of barley in the long run. Therefore, to increase barley yield federal and regional governments have to work lots of research on average DAP replacement and increase on usage of urea fertilizers. The uptake of nitrogen, phosphorus and potassium during the period of barley growth must change based on the characteristics of particular barley varieties. Government may need to make urea fertilizer available to farmers at low cost.

In the presence of climate change the farmers should use different techniques such as irrigation to increase the impacts of precipitation on the yield of barley, since temperature have a negative impact on barley yield, government has to take initiative to introduce the high temperature resistant crops because temperature have an increasing trend.

\section{References}

[1] (CSA), c. s. a., Agricultural sample survey report on Land utilization, in Agricultural sample survey report on Land utilization 2016.

[2] Dorosh, P. and H. Ahmed, Foreign exchange rationing, wheat markets and food security in Ethiopia, 2009, Citeseer.

[3] Matsumoto, T. and T. Yamano, The impacts of fertilizer credit on crop production and income in Ethiopia, in Emerging Development of Agriculture in East Africa. 2011, Springer. p. 59-72.

[4] Ferede, T., et al., Agroecology matters: impacts of climate change on agriculture and its implications for food security in Ethiopia. Global food security: Emerging issues and economic implications, 2013: p. 71-112.

[5] Deressa, T. T. and R. M. Hassan, Economic impact of climate change on crop production in Ethiopia: Evidence from crosssection measures. Journal of African economies, 2009. 18: p. $529-554$.

[6] Lütkepohl, H., New introduction to multiple time series analysis. 2005: Springer Science \& Business Media.

[7] Pesaran, M. H., Y. Shin, and R. J. Smith, Bounds testing approaches to the analysis of level relationships. Journal of applied econometrics, 2001. 16: p. 289-326.

[8] Gujarati, D. N., Basic econometrics. 2009: Tata McGraw-Hill Education.

[9] Pesaran, M. H. and Y. Shin, An autoregressive distributed-lag modelling approach to cointegration analysis. Econometric Society Monographs, 1998. 31: p. 371-413.

[10] Wooldridge, J. M., Introductory econometrics: A modern approach. 2015: Nelson Education.

[11] Engle, R. F. and C. W. J. Granger, Co-integration and error correction: representation, estimation, and testing. Econometrica: journal of the Econometric Society, 1987: p. 251-276. 
[12] Banerjee, A., J. Dolado, and R. Mestre, Error-correction mechanism tests for cointegration in a single-equation framework. Journal of time series analysis, 1998. 19: p. 267283.

[13] Mukaras, M., Fundamental Principles of Time Series Econometrics, Theory and Applications. 2012.

[14] Brown, R. L., J. Durbin, and J. M. Evans, Techniques for testing the constancy of regression relationships over time. Journal of the Royal Statistical Society: Series B (Methodological), 1975. 37: p. 149-163.
[15] Peseran, M. H. and B. Peseran, Working with Microfit 4: Interactive Econometric Analysis, in Working with Microfit 4: Interactive Econometric Analysis 1997, Oxford University Press, Oxford.

[16] Tsadkan, A., The nexus between public spending and economic growth in Ethiopia: Empirical investigation. Unpublished Master Thesis, Addis Ababa University, 2013.

[17] Türsoy, T., Causality between stock prices and exchange rates in Turkey: Empirical evidence from the ARDL bounds test and a combined cointegration approach. International Journal of Financial Studies, 2017. 5: p. 8. 